\title{
Investigating The Role Of Organizational Citizenship Behavior Based on The Padsakov's Model Among Municipal Employees
}

\author{
Narges Javaheri ${ }^{1}$, Behrooz Azerakhsh ${ }^{2}$ \\ ${ }^{1}$ MA in Public Administration \\ Javaheri.narges69@gmail.com \\ ${ }^{2}$ MA student in Business Administration \\ b.azerakhsh1992@gmail.com
}

\begin{tabular}{|c|c|}
\hline ARTICLE INFO & ABSTRACT \\
\hline $\begin{array}{l}\text { Organizational } \\
\text { Citizenship } \\
\text { Behavior } \\
\text { Padsakov's Model } \\
\text { Municipal } \\
\text { Employees }\end{array}$ & $\begin{array}{l}\text { The main objective of this paper is to evaluate the role of } \\
\text { organizational citizenship behavior based on the Padsakov's model. } \\
\text { To achieve this objective, a descriptive survey method has been } \\
\text { used. The statistical population of the study consisted of } 50 \\
\text { municipality employees in Bojnourd. In this research, the effect of } \\
\text { five major factors such as altruism, conscientiousness, chivalry, } \\
\text { civil virtue, and respect and reverence have been investigated. The } \\
\text { questionnaire of Padsakov and colleagues is used. The results of this } \\
\text { research show that the conscientiousness component has the lowest } \\
\text { mean and the altruistic component has the highest mean among the } \\
\text { employees of the municipality and the other components of the } \\
\text { organizational citizenship behavior have a mean and normal mean. }\end{array}$ \\
\hline
\end{tabular}

\section{Introduction}

The completely changing conditions and governing organizations, increasing competition and the need for their effectiveness in such a situation, has revealed their need for a valuable generation of employees more than ever, a generation that is referred to as organizational soldiers. Undoubtedly, these employees are the audit aspect of effective organizations from the non-effective because they act without any expectation in addition to their formal role and effort (Tabarsa, Ramin Mehr, 2010). Today, useful, and voluntary efforts and beyond expectation are referred as behaviors in addition to organizational citizenship roles or behaviors. Most managers also want employees who work more than their jobs. They are looking for employees who go beyond expectations, do some work according to their desire which are not official responsibilities of their job, and generally have a high organizational citizenship behavior. Such behaviors (role and extra-role) are formed based on the perception of reality, not the reality itself. In this regard, if individuals' perceptions of reality are based on fairness and justice, the extra-role behaviors or organizational citizenship behaviors (behaviors) will arise (Ramin Mehr et al., 2009). Accepting that organizational citizenship behavior depends on individual causes to conclude that organizational citizenship behavior is a personality trait and therefore it is a factor that (despite the value for organization) is not easy to manage and control. If the psychological states determine organizational citizenship behavior, the manager may not be able to manage organizational citizenship behavior, but, on the contrary, if organizational citizenship behavior is considered as one of the cognitive evaluative factors of the job and the workplace, management will be able to create this behavior

* Corresponding author E-mail address: b.azerakhsh1992@gmail.com 
and continue (Senobari, 2008). The current world is industrializing with an increasing accelerating. This issue increases the need for innovation, flexibility, productivity, and accountability for the survival and success of organizations. Hence, psychologists emphasize that employees of organizations must go beyond their formal duties. Due to the many interactions with the customer, as well as the nature of service, this concept is more important in the service sectors (Grag and Rastogi, 2006). One of the skills that can help employees in this way is "organizational citizenship behavior." This category refers to individual behaviors that arise from individual insight and, in addition to increasee the efficiency and effectiveness of the organization's performance, are not explicitly encouraged through the formal reward system (Burns \& Carpenter, 2008). Different scientific theories derived from field studies in governmental and private organizations and entities indicate the importance of citizenship behavior as an effective factor in improving individual and organizational performance. According to the conducted studies, organizational citizenship behavior increases managerial and organizational productivity by strengthening the team spirit, cohesion and correlation in the organization, increasing the stability of organizational performance, increasing the organization's adaptation to environmental changes, and ultimately improving the quality of services (Padsakov, 1997).

Katez and Kahen, in their book titled Social Psychology of Organizations, stated that organizations need to have employees that act beyond the requirements of their main roles in the organization in order to effectively perform their duties. They point out that within each work group at a factory, within each section of a government system or even within each unit of a university, there are countless collaborative activities that a limited number of these activities are considered within the job descriptions of employees (Ryan, 2002). And many of them are out-role behaviors (behaviors that are not available in job descriptions in formal and written) that seem necessary to achieve organizational effectiveness. Depending on the concept of extra-role behaviors, behavioral sciences researchers conceptualize the related phenomenon i.e organizational citizenship behavior. In the 1980s, the concept of organizational citizenship behavior was first observed in organizational research literature. There are not many definitions of organizational citizenship behavior, and whatever is defined as the concept, it often derives from the definition of Organ (1983). He says: Organizational citizenship behavior is a unique, optional behavior that is effective in enhancing the effective performance of organization and is not directly or indirectly organized by the official reward system of the organization. Therefore, the components of organizational citizenship behavior can be identified as follows: 1. A type of behavior that occurs beyond the limits specified by the organization by the staff.

2. Behavior that the organization's formal structure does not recognize and encourage it.

3. Behavior that has a significant impact on the performance of the organization (Tabarsa et al., 2010). Accordingly, the components of organizational citizenship behavior based on the Padsakov's model are defined as follows:

1. Donor behaviors (altruism): Donor behaviors include voluntary help to others or prevention of work-related problems. The first part of this definition includes three dimensions of altruism, mediation and encouragement expressed by Organ. The concept of interpersonal helps of Graham \& Williams \& Anderson, interpersonal facilitation of Van Scatter and Motoviltide, and the concept of helping others, George, Bryff, and Jones all represent this category of behaviors. The second part of this definition explains helping others to prevent work problems. 2. Chivalry: Organ defined chivalry as a tendency to endure the inevitable uncomfortable conditions without complaint and discomfort. Chivalry can be defined as the good intention of the staff to tolerate situations that are not ideal without complaint.

3. Organizational loyalty: Includes the concept of goodwill expanding and supporting the organization, George, and the concept of advocacy, supporting and defending the organizational goals, Borman and Motovildo. Organizational loyalty is essential for promoting 
the status of the organization to individuals outside the organization. Supporting and defending against external threats and maintaining commitment even in unfavorable conditions can be seen as loyalty.

4. Corporate compliance: The concept of following organizational rules and procedures that was expressed by Motovildo and Borman illustrates this structure, resulting in the internalization and acceptance of organizational rules, regulations, and procedures, even in the absence of supervision. Therefore, employees who obey all regulations and instructions, even in the absence of supervision, are considered as good citizens.

6. Civil behavior: Civil behavior is as a macro level of interest or commitment to the organization as a whole. Environmental monitoring is an example of these behaviors to identify opportunities and threats, even with personal expense. This behavior reflects the individual's recognition that he is a part of a larger whole. Civil behavior is defined as a behavior that reflects the participation in a company's life

7. Their development: Personal development involves voluntary behaviors of employees in order to improve their knowledge, skills and abilities. The characteristic of such behavior is that learning a new set of skills to develop the scope of participation is done in the organization (Tabrasa and Ramin Mehr, 2010).

\section{Research background \\ Domestic research}

-Askranian and Taheri Attar (2012) conducted a research entitled "Organizational Culture and Its Role in Formation of Organizational Citizenship Behavior from the Viewpoints of the Headquarters Staff of the Ministry of Education". In this study, organizational culture and its role in the formation of organizational citizenship behavior as a goal has been investigated. This is a descriptive study and the field survey method has been used. The research tool was Stephen Robins's organizational culture questionnaire with a reliability of 0.85 and a researcher-made questionnaire of organizational citizenship behavior with a reliability of 0.72 . The sample number are 216 experts from the headquarters of the Ministry of Education who selected by stratified sampling method. Descriptive and inferential statistics such as Pearson correlation and structural equations were used to analyze the data. Findings from structural equations show that organizational culture has the most impact on the formation of organizational loyalty. In addition, organizational culture has a positive effect on the formation of altruism, conscientiousness, organizational participation, decency and organizational compliance.

Zarei Matin et al. (2010) conducted a research entitled "A Comprehensive Model of Factors Influencing the Development of Organizational Citizenship Behavior Case Study: Employees of Iranian National Oil Company". The main purpose of this paper is to present a comprehensive model of factors affecting the development of citizenship behavior in the case study of the Iranian National Oil Company. To achieve this goal, a descriptive survey method has been used. The statistical population of the research includes the personnel of the Iranian National Oil Company (IRI) at the headquarters level in amount of 2500 people and 100 individuals were selected as the statistical sample according to the formula. In this research, the effect of five major factors, leadership style of managers, personality traits of employees, organizational structure, organizational culture and cultural value factors on the development of organizational citizenship behavior have been investigated. The results of this study show that the transformation leadership style of managers, personality traits of employees such as emotional stability, extroversion, experience, compatibility and conscientiousness, dimensions of organizational culture such as process orientation, employee-centered, open system and strict control and social and structural dimensions of social capital, justice and information justice affect the development of organizational citizenship behavior. In this research, 
organizational structure has not been effective on the development of organizational citizenship behavior.

Hassanzadeh Samarin and Sefidkar (2014) conducted a research entitled "The Study of the Relationship between Organizational Virtue and Organizational Citizenship Behavior". The purpose of this study was to investigate the relationship between organizational virtue and citizenship behavior of employees of the municipalities of Rasht city. The method of this study is applied in terms of purpose and is a descriptive-correlation research method that the data is collected using a questionnaire tool and survey method. The managers and experts of the municipalities of Rasht (257 people) were selected as the statistical population and using the Cochran formula, the sample size was determined 154 people. The data collection tool was a questionnaire and the data were analyzed by SPSS software and simple and multiple linear regression test. The findings of the study indicated a positive and significant relationship between organizational virtue and behavior (correlation coefficient of 60.3) between organizational virtue and citizenship behavior of employees in the municipality's areas of Rasht. Also, in investigating the dimensions of organizational virtue and citizenship behavior, optimism (17.9), compassion (20.5), honesty (27.9) and forgiveness (14.4) percent can explain the organizational citizenship behavior of the employees of the municipality's areas.

\section{Foreign Research:}

Zhang et al. (2013) examined the topic of "ethical leadership, organizational citizenship behavior and out-of-work behavior: investigating mediation and process moderation". The present study examines the moderating processes in the relationship between ethical leadership and employee citizenship behavior as well as the out-work behavior using a sample of 277 employees and supervisors from the People's Republic of China. The results showed that negative ethical leadership is related to the policy of perceptions and perceptions that politics, to a degree, negative impact of ethical leadership in the uncertainty of mediation. In addition, the policy of perception interacts with political skill to influence emotional exhaustion through uncertainty. Finally, emotional exhaustion is entirely mediated the behavior of the organizational citizenship uncertainty as well as the uncertainty of the out-work behavior.

Aminu and colleagues (2012) investigated a research titled "Diversity, Organizational Commitment, and Organizational Citizenship Behavior: An Organizational Framework." The purpose of this paper is to examine that labor diversity can produce positive results, such as new and diverse ideas. However, research evidence shows that labor diversity can lead to adverse outcomes. And in this article, there are a number of theories such as social exchange, organizational justice, status, and the theory of mutual relations to illustrate why social exchange is used to perceived injustice in a unique way that results in lower commitment and exclusion from organizational citizenship behavior. Therefore, the main objective of this research is to investigate the role of organizational citizenship behavior based on the Padsakov model among municipal employees.

\section{Materials and methods of research}

Research methods in behavioral science can be divided according to two criteria: a) the purpose of the research; b) how to collect data. The present study, based on the first criterion, is an applied research. Also, scientific research based on how data is collected can be divided into the following categories: a) Descriptive-B-Experimental. The present study is based on a descriptive (field) research according to the data collection method. The purpose of the descriptive research is to describe the facts and characteristics of a phenomenon or a given society in a systematic and precise manner (Delawar, 2003) and the purpose of this research is to gather information to judge the level of citizenship behavior of municipality staff. The meaning of population is the main population from which the representative sample has been 
obtained (Khaki, 2010). The statistical population is a set of individuals, objects, and ... (units) that is common at least in an attribute and usually represented by $\mathrm{N}$. The population of this study is all municipality employees of Bojnourd, which according to the statistics, they are 50 people. In this research, census sampling method was used so all the members of the population were studied. The method of data collection in this research is survey and analysis. In this research, Organizational Citizenship Behavior Questionnaire of Padsakov et al was used to collect comments and data (1990). The questionnaire has 20 closed questions. Regarding the variables determined for measuring organizational citizenship behavior, this questionnaire includes: altruism, conscientiousness, chivalry, civil virtue and respect and reverence. For measuring altruism, questions 1 to 4, conscientiousness, questions 5 to 7, chivalry, questions 8 to 10 , civil virtue, questions 11 to 13 , and respect and reverence, questions 14 to 20 are considered. To evaluate the validity of the tool, the content validity has been used. The content validity of a test is usually determined by people specializing in the subject studies, the questionnaire has been set up by qualified experts using their opinions and pre-testes in a small population, removed its defects. The validity of this questionnaire has been verified by experienced experts. Cronbach's alpha coefficient was used to measure the reliability of the questionnaires. The reliability coefficient of the questionnaire was obtained 0.71 through Cronbach's alpha test in this study.

\section{Results}

In this section, the researcher to answer the problem or decide to reject or confirm the research hypothesis uses different analytical methods. Therefore, it is necessary to note that analysis of the data obtained alone is not enough to find the research questions, interpreting these data is also necessary. First, the data should be analyzed and then interpreted the results of this analysis. In order to describe the characteristics of the sample, descriptive statistics (frequency distribution, mean, standard deviation, statistical charts) are used and then using inferential statistics ( $t$ test, correlation coefficient and regression), the main research question is confirmed or rejected.

\section{Investigating characteristics of the main components studied}

Table (1) - Descriptive statistics of characteristics of the main components studied

\begin{tabular}{|c|c|c|c|c|c|}
\hline SD & Mean & Maximum & $\begin{array}{c}\text { Minimu } \\
\mathrm{m}\end{array}$ & $\begin{array}{c}\text { Frequ } \\
\text { ency }\end{array}$ & $\begin{array}{r}\text { Sariable } \\
\text { (dimensions of } \\
\text { questionnaire) }\end{array}$ \\
\hline 4.84689 & 26.4342 & 38.00 & 16.00 & 50 & Altruism \\
\hline 3.46478 & 15.0921 & 22.00 & 7.00 & 50 & conscientiousness \\
\hline 3.09183 & 21.7368 & 28.00 & 13.00 & 50 & Chivalry \\
\hline 2.02157 & 10.6382 & 16.00 & 6.00 & 50 & Civil virtue \\
\hline 1.93498 & 8.6316 & 12.00 & 3.00 & 50 & Respect and reverence \\
\hline 12.26416 & 63.2632 & 87.00 & 38.00 & 50 & Role of OCB \\
\hline
\end{tabular}

As Table 1 shows, the minimum score of factors of altruism, conscientiousness, chivalry, civil virtue, respect and reverence and success in the OCB is respectively 16, 7, 13, 6, 3, 38, and the maximum of this score is also $38,22,28,16,12,87$. The average of these components is about $26,15,22,11,9,63$, respectively. Therefore, the least mean is related to the component of respect and reverence and the highest mean is related to the altruistic component. 


\section{Investigating the normality status of the main components studied}

The purpose of this study is to investigate the role of organizational citizenship behavior among municipal employees. In such a situation, the best suitable statistical method is the comparison method of theoretical mean with acquisition mean. The comparison of the means has two fundamental assumptions that will be considered first. If the significance level of the Kolmogorov-Smirnov test is more than 5\%, the parametric test of the single-variable t student will be used; otherwise, tests of nonparametric group is used. The two basic assumptions of the $t$ test are: the quantitative of the variables (distance or relative) and the normality of the data that are first examined:

1. The variables (factors of altruism, conscientiousness, chivalry, civil virtue, respect and reverence, and success in $\mathrm{OCB}$ ) are quantitative. 2. Investigating the normality of data The Kolmogorov-Smirnov test was used to evaluate the normality of the data. The results are as follows:

Table (2). Investigating the Normality of the Distribution of Research Variable Data

\begin{tabular}{|c|c|c|c|c|c|l|}
\hline $\begin{array}{c}\text { Role of } \\
\text { OCB }\end{array}$ & $\begin{array}{c}\text { Respect } \\
\text { and } \\
\text { reverence }\end{array}$ & $\begin{array}{c}\text { Civil } \\
\text { virtue }\end{array}$ & Chivalry & $\begin{array}{c}\text { conscienti } \\
\text { ousness }\end{array}$ & $\begin{array}{c}\text { Altruis } \\
\mathrm{m}\end{array}$ & Variables \\
\hline 63.2400 & 8.6400 & 10.6600 & 21.7600 & 15.0600 & 26.4200 & Mean \\
\hline 9.75529 & 1.95626 & 2.02646 & 3.12697 & 3.49583 & 4.90768 & SD \\
\hline 1.068 & 1.464 & 1.077 & .949 & .756 & 1.032 & $\begin{array}{l}\text { Kolmogorov- } \\
\text { Smirnov }\end{array}$ \\
\hline .204 & .28 & .196 & .329 & .618 & .238 & Sig \\
\hline
\end{tabular}

Considering that the significance level of Kolmogorov-Smirnov test in all research variables is more than 5\% (Sig> 0.05), with 95\% confidence, it can be said that the distribution of scores in these variables is normal. Therefore, in the statistical analysis, parametric group tests (t-test and analysis of variance) are used.

\section{Investigating research questions}

In this research, a main research question and five sub-research questions were considered, which the researcher rejects or confirms them using the inferential statistics index (single variable t-test).

In analyzing questions:

The null question indicates that there is no significant difference in the means $(\mathrm{H} 0=0)$ The research question indicates that there is a significant difference in means (H1 $\neq 0)$ The main question of this research is: "What extent is the role of organizational citizenship behavior among municipality's employees?"

Table (3) frequency distribution, mean and standard deviation in the main research question

\begin{tabular}{|c|c|c|c|c|}
\hline SD & $\begin{array}{c}\text { acquired } \\
\text { mean }\end{array}$ & $\begin{array}{c}\text { Theoretical } \\
\text { mean }\end{array}$ & Frequency & Indexes \\
\hline 9.62732 & 63.2632 & 57.5 & 50 & Role of OCB \\
\hline
\end{tabular}


Table (4) assumptions of single variable t test for the main research question

\begin{tabular}{|c|c|c|c|c|c|}
\hline \multicolumn{2}{|c|}{ Test Value (test value=57.5) } & \multirow{2}{*}{ Variable } \\
\cline { 1 - 4 } $\begin{array}{c}\text { Difference of } \\
\text { means }\end{array}$ & Sig & df & $\begin{array}{c}\text { Calculated t } \\
\text { value }\end{array}$ & Critical value t & Role of \\
\hline 5.7632 & .000 & 151 & 7.380 & 1.96 & OCB \\
\hline
\end{tabular}

As Table 3 shows, the acquired mean $(m=63.26)$ and the theoretical mean $(m=57.5)$, the comparison of these two means suggests that the acquired mean of the subjects is higher than their theoretical mean. Also, according to Table (4), which shows the assumptions of the single variable $t$ test for the main research question, it can be said that, on the one hand, the value of $t$ calculated is 7.380 and more than the critical value of $t$ (1.96) with the degree of freedom 151 and on the other hand, considering that the significant level in the table is (0.000) and less than $5 \%$ ( $\operatorname{sig}<0 / 05$ ), the main question is accepted and the null question is rejected. The role of organizational behavior is higher than mean or average.

\section{Test of first sub-question}

The first sub-question of this research is: "What extent is the altruism factor among municipality's employees?"

Table (5) frequency distribution, mean and standard deviation in the first sub-question

\begin{tabular}{|l|l|l|l|l|}
\hline SD & $\begin{array}{l}\text { acquired } \\
\text { mean }\end{array}$ & $\begin{array}{l}\text { Theoretical } \\
\text { mean }\end{array}$ & Frequency & Variable \\
\hline 4.84689 & 26.4342 & 25 & 50 & Altruism \\
\hline
\end{tabular}

Table (6) assumptions of single variable $t$ test for the first sub-question

\begin{tabular}{|c|c|c|c|c|c|}
\hline \multicolumn{2}{|c|}{ Test Value (test value=25) } & \multirow{2}{*}{ Variable } \\
\hline $\begin{array}{c}\text { Difference } \\
\text { of means }\end{array}$ & Sig & df & $\begin{array}{c}\text { Calculated } \\
\text { t value }\end{array}$ & $\begin{array}{c}\text { Critical } \\
\text { value t }\end{array}$ & Altruism \\
\hline 1.4342 & .000 & 151 & 3.648 & 1.96 & \\
\hline
\end{tabular}

As Table 5 shows, the acquired mean $(m=26.43)$ and the theoretical mean $(m=25.00)$, the comparison of these two means suggests that the acquired mean of the subjects is higher than their theoretical mean. Also, according to Table (6), which shows the assumptions of the single variable $t$ test for the first sub-question, it can be said that, on the one hand, the value of $t$ calculated is 3.648 and more than the critical value of $t(1.96)$ with the degree of freedom 151 and on the other hand, considering that the significant level in the table is (0.000) and less than $5 \%$ ( $\mathrm{sig}<0 / 05$ ), the first sub- question is accepted and the null question is rejected. The role of altruism factor is higher than mean or average among municipality's employees.

\section{Test of second sub-question}

The second sub-question of this research is: "What extent is the conscientiousness factor among municipality's employees?"

Table (7) frequency distribution, mean and standard deviation in the second sub-question

\begin{tabular}{|l|l|l|l|l|}
\hline SD & $\begin{array}{l}\text { acquired } \\
\text { mean }\end{array}$ & $\begin{array}{l}\text { Theoretical } \\
\text { mean }\end{array}$ & Frequency & Variabte \\
\hline 3.46478 & 15.0921 & 15 & 50 & conscientiousness \\
\hline
\end{tabular}


Table (8) assumptions of single variable t test for the second sub-question

\begin{tabular}{|c|c|c|c|c|l|}
\hline \multicolumn{5}{|c|}{ Test Value (test value=15) } & \multirow{2}{*}{ Variable } \\
\hline $\begin{array}{c}\text { Difference } \\
\text { of means }\end{array}$ & Sig & df & $\begin{array}{c}\text { Calculated } \\
\text { t value }\end{array}$ & $\begin{array}{c}\text { Critical } \\
\text { value } t\end{array}$ & \\
\hline .0921 & .744 & 151 & .328 & 1.96 & conscientiousness \\
\hline
\end{tabular}

As Table 7 shows, the acquired mean $(m=15.09)$ and the theoretical mean $(m=15.00)$, the comparison of these two means suggests that the acquired mean of the subjects is as their theoretical mean. Also, according to Table (8), which shows the assumptions of the single variable $\mathrm{t}$ test for the second sub-question, it can be said that, on the one hand, the value of $t$ calculated is 0.328 and more than the critical value of $t$ (1.96) with the degree of freedom 151 and on the other hand, considering that the significant level in the table is (0.744) and less than $5 \%$ ( $\mathrm{sig}<0 / 05)$, the second sub- question is rejected and the null question is accepted. The role of conscientiousness factor is not higher than mean or average among municipality's employees.

\section{Test of third sub-question}

The third sub-question of this research is: "What extent is the chivalry factor among municipality's employees?"

Table (9) frequency distribution, mean and standard deviation in the third sub-question

\begin{tabular}{|l|l|l|l|l|}
\hline SD & $\begin{array}{l}\text { acquired } \\
\text { mean }\end{array}$ & $\begin{array}{l}\text { Theoretical } \\
\text { mean }\end{array}$ & Frequency & Variabte \\
\hline 3.09183 & 21.7368 & 17.5 & 50 & Chivalry \\
\hline
\end{tabular}

Table (10) assumptions of single variable $t$ test for the third sub-question

\begin{tabular}{|l|l|l|l|l|l|}
\hline )Test Value $($ test value $=17.5$ & Variable \\
\hline $\begin{array}{l}\text { Difference } \\
\text { of means }\end{array}$ & Sig & df & $\begin{array}{l}\text { Calculated } \\
\text { t value }\end{array}$ & $\begin{array}{l}\text { Critical } \\
\text { value t }\end{array}$ & \\
\hline 4.2368 & .000 & 151 & 16.895 & 1.96 & Chivalry \\
\hline
\end{tabular}

As Table 9 shows, the acquired mean $(\mathrm{m}=21.73)$ and the theoretical mean $(\mathrm{m}=17.5)$, the comparison of these two means suggests that the acquired mean of the subjects is higher than their theoretical mean. Also, according to Table (10), which shows the assumptions of the single variable t test for the third sub-question, it can be said that, on the one hand, the value of $t$ calculated is 16.895 and more than the critical value of $t(1.96)$ with the degree of freedom 151 and on the other hand, considering that the significant level in the table is $(0.000)$ and less than 5\% (sig <0/05), the third sub- question is accepted and the null question is rejected. The role of chivalry factor is higher than mean or average among municipality's employees.

\section{Test of fourth sub-question}

The fourth sub-question of this research is: "What extent is the civil virtue factor among municipality's employees?"

Table (11) frequency distribution, mean and standard deviation in the fourth sub-question

\begin{tabular}{|c|c|c|c|c|}
\hline SD & $\begin{array}{c}\text { acquired } \\
\text { mean }\end{array}$ & $\begin{array}{c}\text { Theoretical } \\
\text { mean }\end{array}$ & Frequency & Indexes \\
\hline 2.2263 & 10.6600 & 2.50 & 50 & Civil virtue \\
\hline
\end{tabular}


Table (12) assumptions of single variable $t$ test for the fourth sub-question

\begin{tabular}{|c|c|c|c|c|l|}
\hline \multicolumn{5}{|c|}{ Test Value (test value $=17.5)$} & \multirow{2}{*}{ Variable } \\
\hline $\begin{array}{c}\text { Difference } \\
\text { of means }\end{array}$ & Sig & df & $\begin{array}{c}\text { Calculated } \\
\mathrm{t} \text { value }\end{array}$ & $\begin{array}{c}\text { Critical } \\
\text { value } \mathrm{t}\end{array}$ & Civil virtue \\
\hline 4.2368 & .000 & 151 & 14.596 & 1.96 & \\
\hline
\end{tabular}

As Table 11 shows, the acquired mean $(\mathrm{m}=10.66)$ and the theoretical mean $(\mathrm{m}=2.50)$, the comparison of these two means suggests that the acquired mean of the subjects is higher than their theoretical mean. Also, according to Table (12), which shows the assumptions of the single variable $t$ test for the fourth sub-question, it can be said that, on the one hand, the value of $t$ calculated is 14.596 and more than the critical value of $t$ (1.96) with the degree of freedom 151 and on the other hand, considering that the significant level in the table is $(0.000)$ and less than 5\% (sig <0/05), the fourth sub- question is accepted and the null question is rejected. The role of civil virtue factor is higher than mean or average among municipality's employees.

\section{Test of fifth sub-question}

The fifth sub-question of this research is: "What extent is the respect and reverence factor among municipality's employees?"

Table (13) frequency distribution, mean and standard deviation in the fifth sub-question

\begin{tabular}{|c|c|c|c|c|}
\hline SD & $\begin{array}{c}\text { acquired } \\
\text { mean }\end{array}$ & $\begin{array}{c}\text { Theoretical } \\
\text { mean }\end{array}$ & Frequency & Indexes \\
\hline 1.9532 & 8.647 & 2.50 & 50 & Respect and reverence \\
\hline
\end{tabular}

Table (14) assumptions of single variable $t$ test for the fifth sub-question

\begin{tabular}{|c|c|c|c|c|l|}
\hline \multicolumn{4}{|c|}{ Test Value (test value=17.5) } & \multirow{2}{*}{ Variable } \\
\cline { 1 - 4 } $\begin{array}{c}\text { Difference } \\
\text { of means }\end{array}$ & Sig & df & $\begin{array}{c}\text { Calculated } \\
\text { t value }\end{array}$ & $\begin{array}{c}\text { Critical } \\
\text { value t }\end{array}$ & Respect and reverence \\
\hline 4.2368 & .000 & 151 & 12.342 & 1.96 & Respent \\
\hline
\end{tabular}

As Table 13 shows, the acquired mean $(\mathrm{m}=8.647)$ and the theoretical mean $(\mathrm{m}=2.50)$, the comparison of these two means suggests that the acquired mean of the subjects is higher than their theoretical mean. Also, according to Table (14), which shows the assumptions of the single variable $t$ test for the fifth sub-question, it can be said that, on the one hand, the value of $\mathrm{t}$ calculated is 12.342 and more than the critical value of $\mathrm{t}(1.96)$ with the degree of freedom 151 and on the other hand, considering that the significant level in the table is (0.000) and less than $5 \%$ (sig <0/05), the fifth sub- question is accepted and the null question is rejected. The role of respect and reverence factor is higher than mean or average among municipality's employees.

\section{Discussion}

In today's challenging world, organizations to compete in the global stage, meeting customers' needs and expectations, and adapting to the changing nature of job, are trying to apply employees who act beyond the task and role assigned in their job descriptions. Because it is believed that these behaviors are reflected beyond the role of performance evaluation, it will affect employees' participation in the programs, and can be a factor in job engagement, organizational commitment, and self-esteem. Batman and Organ (1983) used the term organizational citizenship behavior (OCB), and considered it as useful behaviors that were not 
mentioned in the job description, but the employees preform them to help others in their tasks. The concept of organizational citizenship behavior has created a change in the field of organizational behavior. This concept caused definitely organizations to be innovative, flexible, productive, and responsive to their survival and success (Senobari, 2008). Organizational citizenship behavior requires the variables that provide the basis for it. Most of these variables include features of personality, job satisfaction, organizational commitment, transformational leadership, management control system, leadership style, organizational culture, organizational justice and organizational support. After the context has emerged for these behaviors, the existence of these behaviors in the organization will certainly have implications. Podsakov and his colleagues believe that the study of the predictive factors of organizational citizenship behaviors is one of the important research fields in the field of organizational behavior. The experts in this field believe that a set of conditions must be available within the organization as well as within the staff of the organization in order to be provided emerging such behaviors from the employees (Tabarsa et al., 2010). Today, the importance of the human factor and its unique role as a strategic source and designer and implementer of organizational systems has found a much higher position than the past, where human is considered to be the most important resource and asset for organization in advanced organization thinking. In this regard, today, organizations are trying to achieve rapid growth, continuous improvement, efficiency, profitability, flexibility, adaptability, and readiness for the future and enjoying a privileged position in the field of their activity through sophisticated human resources in a global context to survive, arrange and grow. Take action. Without these qualities, it's really impossible for organizations to be competitive and effective in confronting the best, and in the meantime, organizational citizenship behavior is in priority. The questionnaire of Padsakov et al. was used to investigate this question, and following the survey of each questionnaire, the following results were obtained:

In analyzing the research data and studying the effective components in organizational behavior, the most and the least amount of mean are studied. In this case, the altruistic factors are with the acquired mean $(\mathrm{m}=26.43)$ and the theoretical mean $(\mathrm{m}=25.00)$, the comparison of these two means indicate that the acquisition mean of subjects is higher than their theoretical mean. Because, on the one hand, the value of $t$ calculated is 3.648 and more than the critical value $\mathrm{t}(1.96)$ with the degree of freedom 151, and on the other hand, given that the significance level in the table is (0.000) and less than 5\% ( $\mathrm{sig}<0 / 05$ ), as a result, factors of altruism are more than mean or average, which indicates the high level of interpersonal and voluntary contributions of the municipality employees of Bojnourd. But in the field of conscientiousness, the acquired mean $(\mathrm{m}=26.43)$ and the theoretical mean is $(\mathrm{m}=25.00)$, the comparison of these two means indicate that the acquisition mean of subjects is as their theoretical mean. Because, on the one hand, the value of $t$ calculated is 0.328 and less than the critical value $t$ (1.96) with the degree of freedom 151, and on the other hand, given that the significance level in the table is (0.744) and more than 5\% (sig > 0/05), as a result, factors of conscientiousness are not more than mean or average. Therefore, it can be said that the level of loyalty and support of the organization among the employees is not desirable and it can be said that the municipality did not succeed in implementing this factor among the employees. According to other results, the research of organizational citizenship behavior in Bojnourd's municipality have had acceptable mean.

\section{Reference}

Aminu Mamman, Ken Kamoche, Rhoda Bakuwa, (2012), Diversity, organizational commitment and organizational citizenship behavior: An organizing framework" Human Resource Management Review 22, pp285-302. 
Askariyan, Mostafa Taheri Attar, Fataneh (2012), "Organizational Culture and Its Role in Formation of Organizational Citizenship Behavior from the Viewpoints of the Headquarters Staff of the Ministry of Education" Journal of Research in New Approach in Educational Management, Third Year, Number 2, Pp. 21-34.

Burns T, Carpenter J, (2008), Organizational Citizenship and Student Achievement, Journal of Cross-Disciplinary Perspectives in Education, 1(1), 51 -58.

Garg P, Rastogi R, (2006). Climate profile and OCBs of teachers in public and private schools of India, International Journal of Educational Management, 20(7), 529-541.

Hassanzadeh Samarin, Touraj and Sefidkar, Sepideh (2014), "Investigating the Relationship between Organizational Virtue and Organizational Citizenship Behavior". Journal of Management Studies (Improvement and Development), Year 23 and No. 76, pp. 141-155.

Khaki, Gholamreza (2010), "Method of Research in Management", Tehran: Baztab Publications

Podsakoff, P. M., MacKenzie, S. B., Paine, J. B. , \& Bachrach, D. G. (2000). “Organizational citizenship behaviors: A critical review of the theoretical and empirical literature and suggestions for future research". Journal of Management, 6(3), 513-563.

Podsakoff, P. M., MacKenzie, S. B., Paine, J.B., Bachrach, D. G. (2000). "Organizational Citizenship Behaviors: A Critical Review of the Theoretical and Empirical Literature and Suggestions For Future Research". Journal of Management, 26(3), 513-563.

Podskoff, P. M., Mackenzie, S., Moorman, R. \& fetter, R. (1990), Transformational leader behaviors and their effects on organizational behaviors», The leadership Quarterly, 1, 107 142 .

Ryan, J. J., (2002), "Work Values and Organizational Citizenship Behavior: Values That Work for Employees and Organizations", Journal of Business and Psychology, 17, (1), 123.

Tabarsa, Gholamali and Ramin Mehr, Hamid (2010), "Providing an Organizational Citizenship Behavior Model", Public Management Perspective - Issue 3-, pp. 103-117.

Tabarsa, Gholamali, Hadizadeh, Akram and Koshtegar, Abdolali (2010) "Providing a Model for Explaining the Factors Affecting Organizational Citizenship Behavior", Governmental Perspective - Issue 1, pp. 101-114.

Xiujuan Zhang, Fred O. Walumbwa, Samuel Aryee, Zhen Xiong (George) Chen ,(2013), Ethical leadership, employee citizenship and work withdrawal behaviors: Examining mediating and moderating processes, The Leadership Quarterly 24 (2013) 284-297.

Zarei Matin, Hasan, Alvani, Seyed Mehdi, Jondaghi, Gholamreza and Ahmadi, Fereydun (2010), "A Comprehensive Model of Effective Factors on the Development of Organizational Citizenship Behavior", Case Study: Employees of National Iranian Oil Company, Journal of Public Administration, Vol. 2, No. 3, No. 5, pp. 40-56.

Zohre, Sarmad, Bazargan, Abbas and Elaheh Hejazi (2012), "Methods of Research in Behavioral Sciences", Fifth Edition, Tehran: Agah Publication. -Senobari, Mohammad (2008), "Organizational Citizenship Behavior (Concepts, Definitions, Dimensions and Effective Factors on It)", Human Development of Policemen, Vol. 5, No. 16, 79-99 